\title{
The public's attitude towards doctors' use of Twitter and perceived professionalism: an exploratory study
}

\author{
Authors: Yakup Kilic, ${ }^{\mathrm{A}}$ Devkishan Chauhan, ${ }^{\mathrm{B}}$ Pearl Avery, ${ }^{\mathrm{C}}$ Nigel Horwood, ${ }^{\mathrm{D}}$ Radislav Nakov, ${ }^{\mathrm{E}}$ Ben Disney ${ }^{\mathrm{F}}$ and \\ Jonathan P Segal ${ }^{G}$
}

\begin{abstract}
Introduction
Medical professionals use social media to interact with other healthcare professionals, discuss medical issues and promote healthcare information. These platforms have tremendous power to promote healthcare messages but also have potential to damage the profession if used inappropriately. It is currently unknown how others perceive medical doctors' Twitter activity and, therefore, we conducted an online survey exploring these views.
\end{abstract}

\section{Methods}

We used a Google Forms questionnaire consisting of 21 questions, which we distributed on Twitter, exploring doctors', patients', the public's and other healthcare professionals' views of doctors' Twitter activities. We investigated factors that were associated with mistrust by univariate and multivariate analysis.

Results

Seven-hundred and twenty-six respondents completed the survey. By univariate analysis, a higher proportion of nondoctors reported witnessing unprofessional behaviour and potential breaches of patient confidentiality compared with doctors $(p<0.01)$. In addition, a significantly higher proportion of non-doctors felt that doctors' Twitter accounts should be monitored by both their employer and regulator when compared with doctors. By multivariate analysis, the main predictor of mistrust in the profession were those that had previously witnessed unprofessional behaviour (odds ratio 2.70 ; $95 \%$ confidence interval 2.08-3.33; $\mathrm{p}<0.01$ ).

\section{Conclusion}

There are discrepancies in how doctors and non-doctors view Twitter activity and significant mistrust in the profession was brought about by doctors' Twitter activity. To help limit

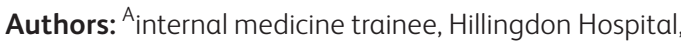
Uxbridge, UK; ${ }^{B}$ geriatrics registrar, Hillingdon Hospital, Uxbridge, UK; ${ }^{C}$ patient safety practitioner, Dorset County Hospital NHS Foundation Trust, Dorchester, UK; D patient advocate, no affiliation; ${ }^{E}$ consultant gastroenterologist, University Hospital Tsaritsa Yoanna, Sofia, Bulgaria; ${ }^{F}$ consultant gastroenterologist, University Hospitals Coventry and Warwickshire NHS Trust, Coventry, UK; ${ }^{G}$ gastroenterology registrar, Hillingdon Hospital, Uxbridge, UK this, adherence to current guidelines set out by the General Medical Council and British Medical Association is vital and doctors should be cautious about how their Twitter activity is professionally perceived by others before posting.

KEYWORDS: social media, healthcare professionals, confidentiality

DOI: $10.7861 /$ clinmed.2021-0357

\section{Introduction}

According to the World Health Organization (WHO), the strategic use of social media can bring public health information to many more people, more quickly and more directly than at any time in history.

With a forecast to reach over 51 million users of social media in the UK, it has had a significant impact on the way the public understand and obtain medical information. ${ }^{2}$ However, healthcare is not immune to the innovative yet potential destructive market forces of social media. Social media transcends geographical boundaries and, in its current form, remains mostly unregulated. ${ }^{3}$ Social media is used by healthcare professionals (HCP) to express opinions, share educational information and engage with other healthcare professionals and wider society. While these platforms potentially provide opportunities to promote positive healthcare messages, there is a balance that needs to be struck in maintaining the profession's reputation and regulation of information shared.

The British Medical Association (BMA) and General Medical Council (GMC) have published guidelines on the use of social media by medical doctors. The guidance emphasises the importance of maintaining the same standards when communicating with the public as they would when face-toface with patients. Particular caution should be taken to ensure confidentiality is not breached through posting patient sensitive material. ${ }^{4,5}$ Doctors have a responsibility to uphold the standards expected of their profession. It is therefore vital to recognise the perception and the impact that their social media activity has towards patients and the wider public. The impact of how social media activities are viewed by peers and patients has not been previously investigated.

The cognitive dissonance between HCPs and the potential impact of their social media conduct can lead to mistrust and damage to the profession. Since 2013, 1,200 staff and 10 doctors have been 
investigated and disciplined for inappropriate social media use. ${ }^{6,7}$ According to the GMC, through a Freedom of Information Act, they reported that in 2019, 118 allegations were made against doctors to the GMC on social media misuse, of which, 27 were taken for further investigation (supplementary material S1; Tables S1 and S3). Out of 27 investigations, the platforms where a breach occurred were nine on Facebook, one on Google, one on Instagram, one on another unspecified platform, two on Twitter, 10 on an unknown platform and three on WhatsApp. One resulted in suspension and one resulted in erasure (supplementary material S1; Table S4).

Twitter is currently the most popular social media platform used to share medical information. ${ }^{8}$ Their remains a paucity of data about the public's and patients' views of doctors' social media activity. This paper aims to evaluate and compare the patients', public's and healthcare professionals' perceptions of medical doctors' Twitter activity.

\section{Methods and materials}

Following a literature review using PubMed, we found no validated questionnaires exploring the role of social media for healthcare professionals. As this was a hypothesis generating questionnaire, we therefore built our own questionnaire based against the recommendations provided by the GMC. Questions were formulated against the GMCs guidance on the Good medical practice principles and questions related to each recommendation from this document. ${ }^{9}$

Utilising the Google Forms online survey tool, a questionnaire was designed to understand how the public perceives medical doctors' Twitter activity. Questions were drafted in a consensus online meeting by the authors. There were two rounds of voting on questions. The questionnaire was then piloted with two patient advocates for feedback. Following two virtual meetings, we included some demographic information for comparison purposes. The original questionnaire contained 30 questions but, after patient feedback, this was limited to 21 questions to ensure the survey was not considered too onerous for respondents to fill in. The final draft was sent to two lay people for critiquing before final approval from all authors (supplemental material S1).

The questionnaire was initially posted on Twitter between 21 December 2020 and 21 February 2021. The hashtags (\#MedTwitter, \#DoctorsTwitter and \#Patients) triggered wider sharing and re-posting of the survey. Participation was voluntary and consent was gained by all respondents to allow answers to be completed anonymously. The survey was discussed with the research and development team at the University of Warwick and as participation was voluntary and anonymous, ethical approval was deemed not necessary. The survey was open for 2 months and results were downloaded as a Google Docs file. Categorical variables were analysed using the chi-squared statistic. Univariate analysis was performed to find factors that were significantly associated with having mistrust in the medical profession. These factors were then carried forward into a multinomial logistic regression model to calculate factors associated with mistrust in the profession. A $p<0.05$ was considered significant. All data analysis was performed in R version 1.4.1106 (RStudio) using the packages 'tidyverse' and 'dplyr'. We reported our findings using the RECORD guideline.

\section{Multinomial regression}

Factors associated with mistrust in the profession were first analysed using univariate analysis using chi-squared. Those considered significant were then taken forward into the multinomial logistic regression (Table 1; supplementary material S1; Table S5).

From multivariate analysis, of those that said that Twitter activity had made them mistrust the profession, the major predictors of mistrust in the profession were those that had previously witnessed unprofessional behaviour (odds ratio (OR) 2.70; $95 \%$ confidence interval (CI) 2.08-3.33; $p<0.01$ ). There were also factors that were associated with a decreased chance of having mistrust in the profession, which included those that believed doctors should be fact checked (OR 0.96; 95\% CI 0.49-1.43), those that felt that professional regulators should monitor doctors' Twitter activity (OR 0.63; 95\% CI 0.05-1.06; $p<0.01$ ) and those that that felt employers should be monitoring doctors' Twitter activity (OR 0.80; 95\% CI 0.22-1.39; $<<0.01$ ).

\section{Results}

A total 728 respondents completed the survey, one response was excluded from the analysis as they ticked both doctor and nurse as demographics. This consisted of $510(70.3 \%)$ that identified themselves as a healthcare professional, of which, 411 (80.6\%) were doctors, $56(11 \%)$ were allied health professionals and 43 $(8.4 \%)$ were nurses. There were $217(29.8 \%)$ respondents who considered themselves either a patient or lay person. Of the 727 who responded, $54 \%$ were women, $44 \%$ were men, $0.8 \%$ were non-binary and $1.2 \%$ preferred not to say (Fig 1). For the multivariate analysis, we analysed data of doctors against all other responders; 411 (56.6\%) doctors and 316 (43.5\%) patients and other HCPs. Baseline characteristics of our respondents are detailed in supplementary material S1, Table S6.

\section{Discussion}

There is growing evidence of the overwhelming benefits of social media use of healthcare professionals. ${ }^{10,11}$ The data found that the majority of respondents supported the sharing of educational content through social media. However, the results identify discrepancies between how doctors and non-doctors perceive Twitter activity. Furthermore, a significantly higher proportion of doctors compared with non-doctors felt it was acceptable to post medical advice on Twitter.

Our findings suggest that non-doctors were more sensitive to perceiving posts as either unprofessional or breaching confidentiality (supplementary material S1; Tables S7 and S8). In addition, a significantly higher proportion of non-doctors felt that doctors' Twitter accounts should be monitored by both their employer and regulator when compared with doctors. Witnessing unprofessional behaviour on Twitter was associated with almost a three-fold increase in having mistrust in the medical profession. Various studies have supported the findings of this study. This includes the advantages of social media to include professional development, improving communication with patients and contributing to public health research and service. ${ }^{12}$ At the same time, other studies have highlighted that when social media is used carelessly, it can lead to a compromise of patient-doctor trust. ${ }^{13}$ Further studies are also in agreement with the findings that social media could pose a risk to patient confidentiality and that unprofessional behaviour has been observed. ${ }^{14,15}$ Importantly, those who felt that regulation of doctors' accounts was important were significantly associated with less chance of having mistrust 
Table 1. Multivariate model associated with those that had mistrust in the medical profession

\begin{tabular}{|c|c|c|c|c|}
\hline \multirow[t]{2}{*}{ Question } & Answer & $\begin{array}{l}\text { Odds } \\
\text { ratio }\end{array}$ & p-value & $\begin{array}{l}95 \% \text { confidence } \\
\text { interval }\end{array}$ \\
\hline & & -3.50 & $<0.01^{a}$ & $-4.32--2.68$ \\
\hline \multirow[t]{6}{*}{ What age group are you? } & $18-29$ years $^{b}$ & $\mathrm{n} / \mathrm{a}$ & $\mathrm{n} / \mathrm{a}$ & $\mathrm{n} / \mathrm{a}$ \\
\hline & $50-69$ years & -0.29 & 0.42 & $-1.01-0.42$ \\
\hline & $<18$ years & -0.40 & 0.68 & $-2.30-1.50$ \\
\hline & Prefer not to say & 13.19 & 0.98 & $-818.60-844.98$ \\
\hline & $>70$ years & 1.97 & 0.22 & $-1.18-5.13$ \\
\hline & $30-49$ years & 0.08 & 0.76 & $-0.40-0.55$ \\
\hline \multirow{3}{*}{$\begin{array}{l}\text { Have you ever witnessed unprofessional behaviour from doctors on } \\
\text { Twitter? }\end{array}$} & $\mathrm{No}^{\mathrm{b}}$ & $\mathrm{n} / \mathrm{a}$ & $\mathrm{n} / \mathrm{a}$ & $\mathrm{n} / \mathrm{a}$ \\
\hline & Not sure & 0.80 & 0.09 & $-0.12-1.72$ \\
\hline & Yes & 2.70 & $<0.01^{a}$ & $2.08-3.33$ \\
\hline \multirow{3}{*}{$\begin{array}{l}\text { Have you ever witnessed an incident on Twitter where doctors could } \\
\text { have potentially breached patient confidentiality? }\end{array}$} & $\mathrm{No}^{\mathrm{b}}$ & $\mathrm{n} / \mathrm{a}$ & $\mathrm{n} / \mathrm{a}$ & $\mathrm{n} / \mathrm{a}$ \\
\hline & Not sure & 0.55 & 0.08 & $-0.06-1.15$ \\
\hline & Yes & 0.96 & $<0.01^{\mathrm{a}}$ & $0.49-1.43$ \\
\hline \multirow[t]{3}{*}{ Do you think Twitter should fact check the content posted by doctors? } & $\mathrm{No}^{\mathrm{b}}$ & $n / a$ & $n / a$ & $\mathrm{n} / \mathrm{a}$ \\
\hline & Not sure & 0.52 & 0.07 & $-0.04-1.09$ \\
\hline & Yes & 0.55 & $0.03^{a}$ & $0.05-1.06$ \\
\hline \multirow{3}{*}{$\begin{array}{l}\text { Do you think doctors' regulators should monitor Twitter accounts in } \\
\text { line with their role of conduct? }\end{array}$} & $\mathrm{No}^{\mathrm{b}}$ & $\mathrm{n} / \mathrm{a}$ & $\mathrm{n} / \mathrm{a}$ & $\mathrm{n} / \mathrm{a}$ \\
\hline & Not sure & 0.33 & 0.32 & $-0.32-0.98$ \\
\hline & Yes & 0.63 & $0.02^{a}$ & $0.08-1.18$ \\
\hline \multirow[t]{3}{*}{ Do you think doctors' employers should monitor Twitter accounts? } & $\mathrm{No}^{\mathrm{b}}$ & $n / a$ & $\mathrm{n} / \mathrm{a}$ & $\mathrm{n} / \mathrm{a}$ \\
\hline & Not sure & -0.20 & 0.56 & $-0.86-0.46$ \\
\hline & Yes & 0.80 & $0.01^{a}$ & $0.22-1.39$ \\
\hline \multirow{3}{*}{$\begin{array}{l}\text { Should doctors be allowed to post adverts and monetise their Twitter } \\
\text { account? }\end{array}$} & $\mathrm{No}^{\mathrm{b}}$ & $\mathrm{n} / \mathrm{a}$ & $\mathrm{n} / \mathrm{a}$ & $\mathrm{n} / \mathrm{a}$ \\
\hline & Not sure & -0.52 & 0.07 & $-1.08-0.05$ \\
\hline & Yes & -0.56 & $0.02^{a}$ & $-1.04--0.07$ \\
\hline
\end{tabular}

in the medical profession. While this is difficult to unpick, it may suggest that levels of professional activity on social media were not considered enough to negatively impact on the levels of mistrust in the profession but suggests that more caution should be applied to medical professional accounts.
The reasons why doctors, patients and non-doctors see trust differently is likely due to the level of understanding of what is required of them professionally on social media. It seems evident that non-doctors were more sensitive to perceiving doctors' posts as either unprofessional or breaching confidentiality.
Fig 1. Distribution of respondents by location and gender.

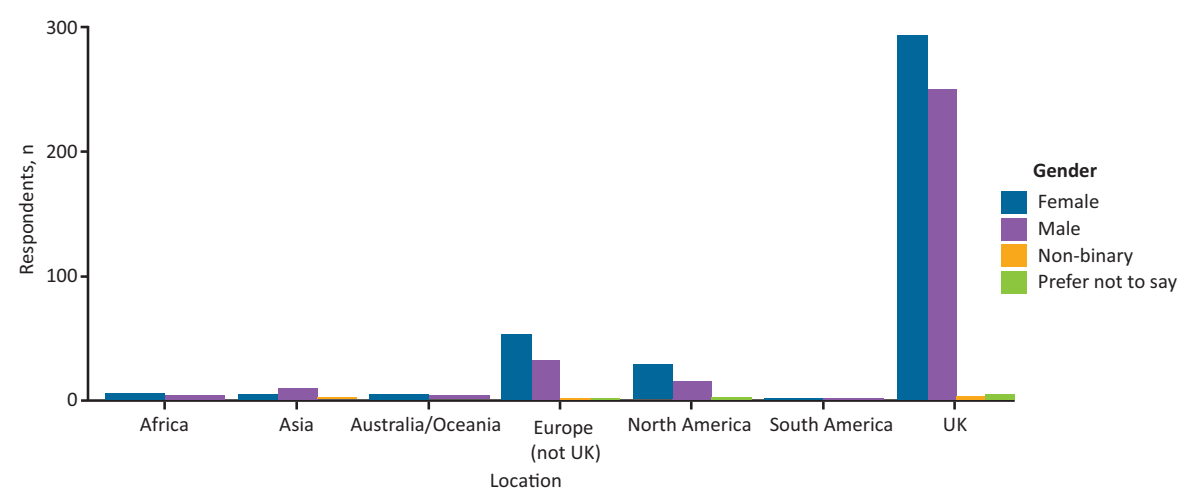


Reasons for this are likely to be manifold, but may include doctors being less aware that posts which would be acceptable in their professional lives may fail to meet this criterion in the eyes of the public. Furthermore, professional discussions that include patient data, while common in the working environment, may be less acceptable to others on a social media platform. Currently the onus is on the non-doctor to decide if the information is from a trusted source or not, and more concerning is that anyone can call themselves a doctor on Twitter as there is no real way of verifying the credentials of an individual. This raises questions about the safety and reliability of medical Tweets from people identifying themselves as doctors and whether some sort of verification should be required before medical learning is shared on this public forum. Moving forward, our findings highlight the current guidance that doctors should not post content that may be perceived as unprofessional or risks patient confidentiality. We also propose that doctors be more aware of how their social media content may be interpreted or perceived by members of the public.

The study has various limitations and is likely to be impacted by various biases. As is the nature of surveys, there is likely to be reporter bias. It is possible that those completing the survey have preconceptions regarding social media use and may have skewed results. Furthermore, the survey was limited to Twitter users disseminated through the authors' Twitter followers, potentially limiting its reach. Furthermore, our survey provided three closed outcomes (yes, no and not sure); we appreciate that, for some questions, this may be a little reductive when it comes to complex issues around social media, but after patient and lay person consultation, it was decided that the simple three options approach would be the easiest when considering all types of respondents. The limitation in numbers means that the survey may not be representative of a wider population. Furthermore, the definition of what constitutes professional and unprofessional behaviour was not explicitly stated in the survey and was open to interpretation by the survey responders. The interpretations are likely to be broad and individual, and therefore may account for discrepancies. Importantly, the amplification of several incidents by a few individuals may cause a wider feeling of distrust with disproportionate impact on nondoctors' perception. Significantly, we believe that the majority of HCPs use social media responsibly and in line with the regulators' guidance and so the results may not be generalisable to all HCPs. Despite these limitations, this remains the largest study to date exploring patients' views of doctors' social media activity.

Moving forward, doctors should be aware that the content they post may be viewed differently by the people they are supposed to serve: patients and the public. It is important to consider what doctors post and avoid any content that may lead to a mistrust in the profession, such as Tweets that may be considered unprofessional behaviour or risk patient confidentiality. The authors recognise the importance of freedom of speech and the benefits of social media to disseminate information and engage in debate. While the authors do not propose a monitoring approach of all social media activity of all NHS employees, it is clear updated guidance is required. Doctors should be cautious that, by identifying themselves on social media as doctors, they should conduct themselves in the same manner that they would in a non-virtual format; this is laid out in the GMC guidance.
Currently, the relationship between a doctor and employer on social media is unclear and individual employers may set different rules compared with the GMC. As a result, having robust guidelines that are reflective of current practice may make the relationship between the employer, employee and GMC more streamlined.

\section{Conclusion}

This survey has highlighted that patients perceive doctors' Twitter activity differently to those of doctors. There is a high incidence of mistrust brought about through doctors' Twitter activity and, hence, doctors should be cognisant of the impact of their social media content. Doctors should adhere to the principles outlined by the $\mathrm{GMC}$ regarding social media use to ensure that social media activity does not put the profession into disrepute. This study also underlines the need to refine social media guidelines for doctors. As social media use becomes more widespread, ethical issues will come to light that would best be approached through guidelines to help deal with online situations.

\section{Supplementary material}

Additional supplementary material may be found in the online version of this article at www.rcpjournals.org/clinmedicine: S1 - Survey questions and results.

\section{References}

1 McNab C. What social media offers to health professionals and citizens. Bull World Health Organ 2009;87:566.

2 Tankovska H. Social media usage in the United Kingdom (UK). statistics \& facts. Statista, 2021. www.statista.com/topics/3236/ social-media-usage-in-the-uk [Accessed 30 April 2021].

3 Cain J, Fink JL. Legal and ethical issues regarding social media and pharmacy education. Am J Pharm Educ 2010;74:184

4 General Medical Council. Doctors' use of social media. GMC, 2020 www.gmc-uk.org/ethical-guidance/ethical-guidance-for-doctors/ doctors-use-of-social-media/doctors-use-of-social-media [Accessed 01 April 2021].

5 British Medical Association. Ethics of social media use. BMA, 2020 www.bma.org.uk/advice-and-support/ethics/personal-ethics/ethicsof-social-media-use. [Accessed 30 April 2021]

6 Rimmer A. Over 1200 NHS staff have been disciplined for social media use. BMJ 2018;362:k3947.

7 Wright J. Group of 10 doctors 'face being struck off for swapping offensive messages over WhatsApp for two years'. MailOnline 2021. www.dailymail.co.uk/news/article-9439063/Group-10doctors-face-struck-swapping-offensive-messages-WhatsApp.html [Accessed 30 April 2021].

8 Pershad Y, Hangge PT, Albadawi H, Oklu R. Social medicine: Twitte in healthcare. J Clin Med 2018:7:121.

9 General Medical Council. Good medical practice. GMC, 2019.

10 Mulrennan S, Colt H. Medical information and social media in the time of COVID-19. Respirology 2020;25:578-9.

11 Zimba O, Radchenko O, Strilchuk L. Social media for research, education and practice in rheumatology. Rheumatol Int 2020;40:18390.

12 Chou WS, Hunt YM, Beckjord EB, Moser RP, Hesse BW. Social media use in the United States: implications for health communication. J Med Internet Res 2009;11:e48.

13 George DR, Rovniak LS, Kraschnewski JL. Dangers and opportunities for social media in medicine. Clin Obstet Gynecol 2013;56: 453-62. 
14 Alshakhs F, Alanzi T. The evolving role of social media in health-care delivery: measuring the perception of health-care professionals in Eastern Saudi Arabia. J Multidiscip Healthc 2018;11:473-9.

15 Segal JP, Hansen R. Medical images, social media and consent. Nat Rev Gastroenterol Hepatol 2021;1-2 [Epub ahead of print].
Address for correspondence: Dr Jonathan Segal, Hillingdon Hospital, Pield Heath Road, Uxbridge UB8 3NN, UK.

Email: jonathansegal1@nhs.net

Twitter: @DrYakupKilic1; @Jonathansegal85 